\title{
Problems in Experimental Teaching Management of Comprehensive Art Institutions and the Countermeasures
}

\author{
Lei Zhang \\ Huanghe Science and Technology College \\ Zhengzhou, China
}

\begin{abstract}
This paper mainly probes into the problems in art experimental teaching management. After clearing the problems in experimental teaching management, this paper respectively discusses the problems in art experimental teaching and the solutions from three respects: course scheduling pattern, planning and construction of laboratories and classroom teaching pattern of art experimental course.
\end{abstract}

Keywords-art experiment; teaching management; problems; countermeasu res

\section{INTRODUCTION}

The concept of art experiment comes into being late in comprehensive colleges, so the teaching management of art experiment just copies the experiment management system of science and engineering. The management methods of science and engineering are adopted to manage the experiment of art, which leads to the chaos that may have bad impact on students' learning quality and bring about severe inconvenience to the teaching management of art experiment, of art experimental teaching management system. The problems embody the unbalance of laboratory arrangement, ambiguity of duty division among professional teachers and laboratory technician and incoherence of curriculum scheduling.

\section{PROBLEMS IN ART EXPERIMENTAL TEACHING MANAGEMENT}

\section{A. Ambiguity of the Concept of Experimental Teaching Management}

The ambiguity of the concept of art experimental teaching management includes the following aspects: First, admin is trative orders are superior to the laws of experimental teaching. Administration in college and university management is the chronic problems in China's current higher education; the interference of administration in art experimental teaching management is very apparent as well. Second, the cultivation objective of art experimental teaching is obscure. With the development of society, the classification of art categories is increasingly elaborate, and more and more art categories come into being. Traditional art cultivation scheme cannot meet the needs of current society for art talents anymore, which embodies in experimental teaching is that regular art experimental courses cannot meet the needs of students for new art form learning. Third, randomness exists in teaching process management. To implement the cultivation objective is dependent on scientific and reasonable teaching process management. However, there are unhealthy phenomenon such as distinct alienation between teacher and student, among teachers and obsolete teaching approaches in art experiment teaching.

\section{B. Non-Scheduling and Randomness in Laboratory Construction}

Since art specialties are unfamiliar with "laboratory", and ignored the planning of "experimental teaching system" when scheduling the subject system, the construction of "laboratory" is respectively arbitrary. Although that have planed the laboratory construction, the panning is more like a cloud-castle. On the one hand, due to the influence of administrative management, the leadership has a divergence on the importance of different part of the construction, which may lead that to that laboratory construction cannot catch the steps of planning. On the other hand, the laboratory construction is more like a vanity project, and the fundamentality construction of laboratory is neglected. For example, more than one decade ago, Apple computer dominated the graphic design area, but now PCs have totally occupied the area. Teachers and students now have already got used to PCs and the Apples are marginalized. Continuing construction Apple computer room means a waste of money. However, in real application, Apple computers are usually installed with Windows; Apple comports are used as PCs, which indicates that the course structure of art specialized experimental course is not stable and laboratory construction are not well-planned.

\section{Defective Experimental Teaching Process Management and Inadequate Research on Experimental Teaching Approaches}

There are many factors that restrain the development of art experimental teaching of colleges and universities, among which incomplete experimental teaching process management and obsolete experimental teaching approaches have restrained the development of art teaching the most. We should dully take advantage the convenience brought by hi-tech; for 
example, we are supposed to fully make use of the convenient conditions created by the network to stimulate students' enthusiasm and to initiate new experimental approaches that can bring students joy and knowledge.

\section{Lacking Experimental Teachers, Unreasonable Structure of Experimental Staff}

To construct a good experimental teachers' team is the foundation of art experimental teaching system; any good experimental equipment's function relies on good teaching concepts, teaching pattern and teachers. Due to the particularity of art specialty laboratory, to construct a high quality experimental teaching team is a significant step in the construction of art experimental teaching system. However, in current art experimental teaching system, the construction teachers' team is quite weak: the quantity of art experimental teachers is inadequate; the status of experimental teachers is respectively low; the quality of experimental teachers is not high etc.. Experimental technicians do not have professional background, usually cannot bear management duty in experiment position. What's more, due to their lack of specialty research, art experimental teaching system is in a state of non-research. Is sues related to laboratory teachers are the most puzzled and difficult problems in the construction and development of art specialties. In all, experimental teachers' team construction has been ignored for a long time, which makes the problems the most difficult problem to restrain the development of experimental teaching reform.

\section{E. Low Utilization Ratio of Experimental Resource and Inadequate Resource Sharing}

Recent years, art education combines comprehensiveness and specialty, the voice of sharing art experimental resources is louder and louder; to break through the boundaries among schools is the orientation to share art experimental resources. However, previous laboratory construction is independently conducted by different schools and specialties, so the completed laboratories become the private properties of corresponding schools. Due to the experiment management system and human factors, sharing the art experimental resources cannot be carried out well. What's more, in terms of utilizing the equipments, independent laboratory construction and management result in repeated procurement of equip ments, which lowers the utilization ratio of experimental equip ments and wastes experimental resources. Although the problem has been realized on the level of colleges and experimental resources have been integrated and shared, the actual result is not promising. Other schools' using the art experimental resource is inconvenient to applying for and not wellsupported technically. In addition, the configuration of technicians, work load calculation, consumption of experiment materials and maintenance of equipments are faced with various difficulties. To dig into the sharing mechanism of art experimental resources and to enhance the utilization ratio of resources are the important content of experimental teaching system.

\section{COUNTERMEASURESTO IMPROVE ART EXPERIMENTAL} TEACHING MANAGEMENT

\section{A. To Alter the Current Stage Course Scheduling Pattern into Paralleling Course Scheduling Pattern}

As for the present situation, compared with paralleling course scheduling pattern, stage course scheduling pattern have more disadvantages than advantages. First, stage course scheduling pattern bring more difficulties to the management of students. The scheduling is unbalanced and there are many hazards in the management; second, stage course scheduling pattern has lower efficiency than paralleling course scheduling pattern. Because of centralized course arrangement, teachers have to spare more time to the students for their in-class selfstudying or skill drilling, which results in the waste of class time and students may have nothing to do after class. Besides, the course lasts for a short time and students do not have much time to digest the course; therefore, the efficiency is decreased. It often happens that when students just have a surface understanding of the course, but it is over. At present, an area that students do not have much desire to learn, few students are willing to dig into this course anymore.

However, paralleling course scheduling pattern can avoid such problems brought by stage course scheduling. The advantage of this pattern is that it can extend the course time to the whole semester. The periods can be fully ensured; students will not have the feeling of being crammed and will have to digest what the teacher has taught. Besides, the teacher will not be in a over-stressed state and over-tired. In terms of teaching methods, discussing teaching will be adopted, and the class teaching pattern will be mainly discussion and evaluation. The two-hour class will be the precious opportunity for thinking and communication; besides, the communication will be quite deep, and students' language competence can be trained. Apart for making full use of class time, students can also take advantage after-class time to prepare and collect materials until they accomplish the task. Compared with stage course scheduling pattern, paralleling scheduling pattern is more suitable for students to increase efficiency.

\section{B. To Improve the Planning and Construction of Laboratory}

In terms of planning the laboratory, we should stick to the following principles: first, in line with the development of specialty, to overall plan it. The laboratory is not only the main spot to conduct experimental teaching; it is also the important research base of teaching research and safeguard to cultivate innovative talents. Therefore, the construction of laboratory must be in line with the development of specialties and to construct art practice center that meet the requirements of experimental teaching, teaching research and art talent cultivation. What's more, we should also improve the construction of laboratory and the reasonable input of equipments. In order to enhance the scientific research level and cultivation quality, first, do well in the overall planning of laboratory. The overall planning of laboratory must be based on the subject development and students cultivation objectives. The laboratory planning based on such a premise is scientific and reasonable, and it will be the guideline to the instruction of laboratory. The construction of laboratory should be 
implemented step by step under the instruction of the plan; second, to conduct art laboratory planning with the principle of experiment intensification. Traditional laboratories are usually affiliated to the schools and specialties; different laboratories are separate. There are more walls than paths among laboratories, which is not good for the interaction and penetration among art experimental courses and the developing the performance of instruments and equipments and fluent carrying out of open experimental projects; third, to improve the digitization, networking and informatization construction of the laboratory. Provide a powerful hardware support for the implementation of open experimental projects. Through the sharing of laboratory resources, exert the function of the laboratory and scale efficiency and construct a large laboratory platform with radioactivity that aims to cultivate new art talent.

In laboratory construction, we should adhere to the following principles: 1. Sharing priority: limited fund resources should be inclined to high-sharing laboratory projects to increase the utilization efficiency of specialized laboratory. Definitely, sharing and opening will bring about some new problems in management; for instance, the rate of damage and failure, experimental consumption materials and work load of management staff will increase. Therefore, the college should give more support in laboratory construction and maintenance fund. 2. Student-orientated principle: The purpose to construct the laboratory is to propel the development of students' specialty ability, to provide a good learning environment, hardware facilities and humanistic experimental ecological system for students' specialty learning, which may lay s solid foundation for students' development and hardware safeguard. First, the laboratory should be equipped on accordance with the contents of experimental teaching, and the perspectiveness of instruments should be guaranteed; then, a good experimental environment can be provided. In addition, the software construction of the laboratory should be improved. In consideration of teachers' and students' psychological and physical features, humanistic design and decoration should be equipped with the laboratory environment to increase the efficiency of laboratory. With teachers' and students' personal safety ensured, they can complete experiment and teaching tasks in a healthy and comfortable condition.

\section{To Enhance the Integration Capability of Art Experimental Course and Modern Education Technology}

There are two approaches to enhance the integration of art experimental course and modern education technology. The first one is to apply education technology approaches to experimental course. For example, with the development of science and technology, a lot of experiments are becoming easier and many new teaching methods and approaches are provided for experiment. Digital virtual experiment teaching system is a virtual experiment system combining experiment, network technology and multimedia. By multi expression forms, the system can present experimental theories and knowledge such as experimental outline, experimental principle, purpose and requirement of experiment and experimental equip ments.
Through demonstrating courseware and experimental video, students can learn the points for attention and others' experience information. Students can not only watch the simulation process, but also operate simulation experimental courseware by themselves. By changing the operation parameters, students can clearly know the relationships between parameters and results in animation, audio and visual software. Through the interaction between students and virtual experimental system, students can have a more direct and deep understanding of experimental information. To use modern education technology approach to change traditional teaching method. For example, by vidicon the teacher can record students' performance process, then point out the incorrect part Students can enhance the ability to correct mistakes, and the sufficiency of class will be increased. Another example is that with the widespread of smart phones, the timely feedback of training effect after experimental course is possible. The training effect of traditional classroom teaching is usually demonstrated by class performance. However, with the expansion of student scale and modern college students' unbounded personality, the result of class test usually cannot reach the expected status, which will inevitably have negative effect on the schedule of the course. With the popularity of smart phones, students can upload their performance video to the appointed place; then, the teacher will have a better mastery of students' status. After that, the teacher can conduct pertinence experimental teaching to improve the result of experimental teaching.

\section{REFERENCES}

[1] Zhang Jianping, Wang Yuwen \& Wu Zhijiang. The Research and Construction of the Teaching System for the Arts Specialty in Local Engineering Colleges [J]. Experimental Technology and Management, 201010 .

[2] Wu Aoran, Wang Ping, Huang Huaming \& Liu Zhineng, Innovation of Experimental Teaching Mode of Art Design Major on Colleges and Universities [J]. Data of Culture andEducation, 200621.

[3] Li Ling, On the Experimental Teaching of Public Art Experimental Center [J]. Research and Exploration in Laboratory, 20058.

[4] Fan Min \& Jiang Zhihua, Construction and practice of experimental teaching system in art academy [J]. Experimental Technology and Management, 20101.

[5] Zhang Jie, Experimental Teaching and Arts Education-Thinking of laboratory Establishment and Experimental Teaching of Sichuan Fine Arts Institute [J]. Research and Exploration in Laborat ory, 20111.

[6] Zhu Xiang \& Sun Shujia, Thoughts and Exploration on the Reform of Art Design Experimental Teaching [J]. Research and Exploration in Laborat ory, 20112. 